\title{
Paracrine interactions between primary human macrophages and human fibroblasts enhance murine mammary gland humanization in vivo
}

Jodie M Fleming ${ }^{1,2,3^{*}}$, Tyler C Miller, Michal Kidacki ${ }^{1}$, Erika Ginsburg ${ }^{1}$, Christina H Stuelten ${ }^{2}$, Delisha A Stewart ${ }^{4}$, Melissa A Troester ${ }^{4}$ and Barbara K Vonderhaar ${ }^{1}$

\begin{abstract}
Introduction: Macrophages comprise an essential component of the mammary microenvironment necessary for normal gland development. However, there is no viable in vivo model to study their role in normal human breast function. We hypothesized that adding primary human macrophages to the murine mammary gland would enhance and provide a novel approach to examine immune-stromal cell interactions during the humanization process.
\end{abstract}

Methods: Primary human macrophages, in the presence or absence of ectopic estrogen stimulation, were used to humanize mouse mammary glands. Mechanisms of enhanced humanization were identified by cytokine/ chemokine ELISAs, zymography, western analysis, invasion and proliferation assays; results were confirmed with immunohistological analysis.

Results: The combined treatment of macrophages and estrogen stimulation significantly enhanced the percentage of the total gland humanized and the engraftment/outgrowth success rate. Timecourse analysis revealed the disappearance of the human macrophages by two weeks post-injection, suggesting that the improved overall growth and invasiveness of the fibroblasts provided a larger stromal bed for epithelial cell proliferation and structure formation. Confirming their promotion of fibroblasts humanization, estrogen-stimulated macrophages significantly enhanced fibroblast proliferation and invasion in vitro, as well as significantly increased proliferating cell nuclear antigen (PCNA) positive cells in humanized glands. Cytokine/chemokine ELISAs, zymography and western analyses identified TNF $\alpha$ and MMP9 as potential mechanisms by which estrogen-stimulated macrophages enhanced humanization. Specific inhibitors to TNF $\alpha$ and MMP9 validated the effects of these molecules on fibroblast behavior in vitro, as well as by immunohistochemical analysis of humanized glands for human-specific MMP9 expression. Lastly, glands humanized with macrophages had enhanced engraftment and tumor growth compared to glands humanized with fibroblasts alone.

Conclusions: Herein, we demonstrate intricate immune and stromal cell paracrine interactions in a humanized in vivo model system. We confirmed our in vivo results with in vitro analyses, highlighting the value of this model to interchangeably substantiate in vitro and in vivo results. It is critical to understand the signaling networks that drive paracrine cell interactions, for tumor cells exploit these signaling mechanisms to support their growth and invasive properties. This report presents a dynamic in vivo model to study primary human immune/fibroblast/epithelial interactions and to advance our knowledge of the stromal-derived signals that promote tumorigenesis.

\footnotetext{
* Correspondence: jodie.fleming@nccu.edu

'Mammary Biology and Tumorigenesis Laboratory, Center for Cancer

Research, National Cancer Institute, Bethesda, MD 20892, USA

Full list of author information is available at the end of the article
} 


\section{Introduction}

Mammary gland development and function depends on intricate interactions of the functional epithelial cells with local stromal cells, including fibroblasts, adipose, endothelium, immune and nerve cells [1-4]. The mammary gland is a particularly unique organ as the majority of its development occurs postnatally. Systemic and locally produced steroids and growth factors orchestrate the outgrowth and differentiation of the epithelium throughout the gland during puberty, followed by additional rounds of proliferation and differentiation during pregnancy, lactation, and involution [1,3]. Furthermore, analyses of breast tissue from human autopsy and surgical specimens suggest that additional morphologic changes in the epithelium repeatedly occur during each menstrual cycle [5]. These morphological changes are a result of hormone- and growth factor-stimulated alterations in proliferation, apoptosis, protein expression, and cell kinetics. It is critical to understand the signaling networks that drive these cyclic changes, for many of the signaling mechanisms that control them are often exploited by tumor cells to support their growth and invasive properties.

Much of our knowledge about these processes in the human breast has been extrapolated from mouse and rat models. Attempts to recapitulate human breast morphogenesis in the mouse mammary gland using direct injections or collagen embedded cells failed to support proliferation of breast epithelial cells in mouse models. However, injection of human breast fibroblasts into the cleared mammary fat pad prior to injection of human breast epithelial cells (xenograft humanized mammary gland model) [6] stimulates human epithelial cell proliferation and promotes the organization of differentiated acini structures, and leads to successful engraftment of mouse mammary fat pads with human breast epithelial cells. This innovative model allows the investigator to observe fibroblast-epithelial interactions, with either normal or cancer-derived cells, in an orthotopic in vivo model.

In addition to fibroblasts, the homeostasis of breast epithelial cells depends upon interactions with many different types of stromal cells. In particular, macrophages comprise a vital, functional component of the mammary microenvironment and are essential for normal mammary gland development [7-10]. During development, macrophages are recruited and localized in abundance to the neck of the developing terminal end buds. Their removal during postnatal development by either genetic manipulation or gamma irradiation results in reduced formation of terminal end buds and restricted outgrowth and branching of the epithelial ductal tree $[9,11]$. Although a plethora of data suggests a central role for macrophages during mammary development, the precise mechanisms remain unknown. It is hypothesized that they promote epithelial growth throughout the gland by supplying growth factors, proteases, cytokines and angiogenic factors [12].

Macrophages play a role not only in normal mammary development but also in breast cancer development, progression, and metastasis. Consistent with cellular alterations that occur during tumorigenesis, tumor-associated macrophages (TAMs) display distinct phenotypes and behavior compared to those in non-malignant tissue [13]. TAMs secrete proteases that facilitate degradation of basement membrane and extracellular matrix for facilitation of tumor invasion and metastasis. Additionally, TAMs supply epidermal growth factor (EGF) and Wnt ligands that promote cell growth and vascular remodeling, respectively [14-16]. Clinical data support these observations; for example, a high density of TAMs is correlated with poor prognosis and decreased survival in breast cancer patients [16-18].

Given the fundamental role macrophages perform in mammary development and function, as well as during tumorigenesis, we hypothesized that the introduction of human macrophages would enhance humanization of the murine mammary gland and permit an intimate first look at human immune and stromal-derived paracrine cell interactions in a dynamic in vivo model. Herein, we demonstrate that primary human peripheral blood macrophages enhance humanization by enhancing fibroblast proliferation and engraftment of the mammary fat pad, thereby providing a larger stromal bed for breast epithelial growth and acini formation. We have identified two specific paracrine mechanisms involved in enhancement of humanization: increased fibroblast proliferation stimulated by macrophage-derived TNFa as well as a macrophage-stimulated increase in matrix metalloproteinase (MMP)-9 expression and proteinase activity. Collectively, our data demonstrate intricate mechanisms of primary human immune and stromalderived paracrine interactions in a humanized xenograft model of the mammary gland.

\section{Materials and methods}

\section{Collection and processing of patient samples and cell culture}

Collection of patient samples was performed in accordance with the guidelines of the National Cancer Institute's Institutional Review Board, under four separate approved protocols OH99-C-NO57, 02-C-0077E, 04-C0199, OHSR4789, and 99-CC-0168. Written informed consent was obtained from all human subjects as stipulated by the protocols. Breast tissue was collected from premenopausal fasting patients undergoing reduction 
mammoplasty. The tissue obtained for analyses was considered pathological medical waste; thus, any clinical details of the women, apart from age and race, were unattainable. A pathologist confirmed that each sample was free of malignant or hyperplasic growth. Immediately after surgery a portion of tissue was used for epithelial cell and organoid isolation as described [19]; an additional separate piece of tissue was used for isolation of primary human breast fibroblasts, and the remainder was snap frozen and stored at $-80^{\circ} \mathrm{C}$. Fibroblasts were isolated by placing $<5 \mathrm{~mm}$ pieces of tissue on a scratched cell culture dish, and with time, the fibroblasts crawled out of the tissue to form a monolayer on the dish. The fragments of tissue were removed and the remaining fibroblasts were passaged and plated as monolayer cultures, to expand and ensure fibroblast purity. When necessary, epithelial cells were separated from the stromal cells by differential trypsinization and selective pressure with fibroblast growth medium, DMEM containing 10\% FCS (Invitrogen, Gaithersburg, MD, USA). Fibroblasts were grown for a maximum of three passages prior to analysis. Human telomerase reverse transcriptase (hTERT)-immortalized breast fibroblasts were a kind gift from Charlotte Kuperwasser (Tufts University, Boston, MA, USA).

Peripheral blood monocytes and macrophages were collected from premenopausal women undergoing apheresis. Monocytes and macrophages were separated from other cells using Ficoll-Hypaque (Sigma, St. Louis, MO, USA) gradient separation and selection by adherence to tissue culture plastic. Cells were grown in RPMI containing 5\% human serum (Invitrogen) for $24 \mathrm{hr}$ then changed to RPMI containing 5\% FBS until differentiation. Differentiation was performed via treatment with $20 \mathrm{ng} / \mathrm{ml}$ of IFN $\gamma$ and lipopolysaccharide (LPS, Sigma) in $2 \%$ charcoal-stripped serum (Hyclone, Logan, UT, USA) for $48 \mathrm{hr}$.

T47D breast cancer cells were obtained from American Type Tissue Culture Collection (Manassas, VA, USA) and maintained in RPMI1640 (Invitrogen, Gaithersburg, MD, USA) supplemented with 5\% heatinactivated FBS (Invitrogen), $10 \mu \mathrm{g} / \mathrm{ml}$ bovine insulin (Sigma, St. Louis, MO, USA), and 100 units $/ \mathrm{ml}$ penicillin-streptomycin (Invitrogen). All cells were maintained at $37^{\circ} \mathrm{C}$ in a humidified atmosphere with $5 \% \mathrm{CO}_{2}$. Cells were passaged using trypsinization (0.05\% trypsin- ethylenediaminetetraacetic acid (EDTA), Invitrogen) and counted on a hemocytometer using trypan blue exclusion.

\section{Humanization models}

Animal experiments were conducted in accord with accepted standards of humane animal care and approved by the Animal Care and Use Committee at the National
Institutes of Health, USA. Female, 3-week-old NOD/ SCID mice were randomized into groups with a minimum of five mice per group (APA, Frederick, MD, USA). Mice were anesthetized using inhaled isoflurane (1.0 to $2.5 \%$ ) vaporized in oxygen, with an intraperitoneal injection of analgesic (Sensorcaine) prior to surgically exposing the abdominal mammary fat pad for injection. Both abdominal mammary glands were humanized as previously described [19] with the following additional steps performed where indicated: mice were supplemented with estrogen via a subcutaneous pellet (0.72 mg $\beta$-estradiol, 90-day release; Innovative Research of America, Sarasota, FL, USA) at the time of initial fibroblast injection. Primary human macrophages $(7.5 \times$ $10^{5}$ ) were injected during both the initial fibroblast injection and second injection of fibroblasts along with primary breast epithelial cells/organoids. Mice were euthanized two months after final injection; glands were removed and immediately imaged and/or fixed in $10 \%$ neutral buffered formalin, paraffin-embedded and sectioned. For experiments evaluating fibroblast outgrowths in the presence or absence of macrophages, the same steps were performed as described above without the addition of primary breast epithelial cells/organoids; glands were harvested 10 days after final injection and tissues were processed as described.

\section{Tumor formation assays}

The right abdominal mammary glands were humanized $+/$ - macrophages and the mice were supplemented with estrogen via a subcutaneous pellet, as described above (five mice were injected for each treatment group). Primary human macrophages $\left(7.5 \times 10^{5}\right)$ were injected during both the initial fibroblast injection and second injection of fibroblasts along with $1 \times 10^{6}$ T47D breast cancer cells. Tumor growth was measured using calipers on a weekly basis. Final tumor volume was calculated $((0.5 \times \mathrm{L}) \times(0.5 \times \mathrm{W}) \times(0.5 \times \mathrm{H}) \times(4 / 3) \times(\Pi))$.

\section{Comparative PCR expression analysis of differentiated macrophages by colony stimulating factor-1 (CSF-1) or LPS and INF $\gamma$}

Peripheral blood monocytes were collected from premenopausal women undergoing apheresis and isolated as described above. Differentiation was performed via treatment with $20 \mathrm{ng} / \mathrm{ml}$ of IFN $\gamma$ and LPS or $50 \mathrm{ng} / \mathrm{ml}$ of CSF-1 (Peprotech, Rocky Hill, NJ, USA) in 2\% charcoalstripped serum for 5 days. RNA was isolated using the RNeasy kit (Qiagen, Valencia, CA, USA). RNA purity and integrity were confirmed by Agilent 2100 Bioanalyzer. RNA samples (100 ng/sample) were converted into cDNA (Qiagen) and plated on custom-designed PCR arrays (SA Biosciences) containing 43 macrophage differentiation and polarization genes [20] to determine the 
concordance of macrophage differentiation between the two treatment protocols. Real-time quantitative PCR analysis was performed according to the manufacturer's protocol using an Applied Biosystems 7900HT Fast PCR machine. PCR thresholds were identically adjusted then raw cycle threshold (CT) values were uploaded into the SA Biosciences webpage for comparative analysis, where the CSF-1-treated cells were designated as the reference control. The $P$-values for the averaged relative gene expression between the glyceraldehyde 3-phosphate dehydrogenase (GAPDH)-normalized CSF-1 versus LPS and INF $\gamma$ treated cells were retrieved and can been seen in Additional File 1, Table S1 with the average change in cycle threshold $(\Delta \mathrm{CT})$ values. A two-tailed $t$-test confirmed no significantly differential expression between the two treatment groups across all genes $(P=0.7275)$. Only four genes were significantly differentially expressed, based on P-values (BIRC3, CCR7, CD163, and $P T X 3)$.

\section{Fluorescence in situ hybridization analysis (FISH) Antigen retrieval}

Slides were de-paraffinized by three treatments in xylene and then dehydrated in $100 \%$ ethanol (Sigma). Antigen retrieval (pepsin) was performed using the Histology Kit (Dako, K5599; Carpinteria, CA, USA) according to the manufacturer's instructions, followed by two washes with $2 \times$ SSC (saline-sodium citrate buffer; $0.3 \mathrm{M} \mathrm{NaCl}$, $30 \mathrm{mM}$ trisodium citrate, $\mathrm{pH}$ 7.0)). Specimens were then dehydrated in an ethanol series and allowed to dry.

\section{Preparation of chromosome paint}

The chromosome paint was obtained as previously described by chromosome flow sorting [21], followed by degenerate oligonucleotide-primed PCR amplification [22]. The flow-sorted probe was labeled with biotin-16dUTP, and in situ hybridization of the probe was performed in a $5 \mu \mathrm{l}$ volume. The mixture was precipitated and dissolved in $14 \mu \mathrm{l}$ of hybridization buffer (formamide $50 \%$, dextran sulfate $10 \%, 2 \times$ SSC). The probe was denatured at $80^{\circ} \mathrm{C}$ for 10 minutes and re-annealed at $37^{\circ} \mathrm{C}$ for 90 minutes before hybridization.

\section{In situ hybridization}

The previously prepared slide was denatured in $70 \%$ formamide $/ 2 \times \mathrm{SSC}$, at $65^{\circ} \mathrm{C}$ for $80 \mathrm{sec}$, and quenched in an ice-cold $70 \%$ ethanol followed by dehydration in $70 \%$, $90 \%$, and $100 \%$ ethanol series at room temperature. Hybridization was carried out in a humidified chamber at $37^{\circ} \mathrm{C}$ overnight. Slides were washed and counterstained with diamidino-2-phenylindole (DAPI, $0.8 \mathrm{ng} / \mu \mathrm{l}$ ) for 10 minutes and the slides were mounted with antifade.

\section{Microscopy}

Analyses were performed under an Axioplan 2 (Zeiss) fluorescence microscope coupled with a CCD camera (Photometrics), and images were captured with
FISHview 4.5 software (Applied Spectral Imaging Inc., Vista, CA, USA).

\section{Quantitative real-time PCR (RT-PCR)}

Total RNA was isolated from primary human monocytes/macrophages or humanized glands using the RNeasy kit (Qiagen) according to the manufacturer's instructions. RNA was reverse transcribed using MMLV reverse transcriptase (Invitrogen) and primed with oligo$\mathrm{dT}$ and random hexamers (Invitrogen). The cDNA was amplified using gene-specific primers for CD14, CD68, acyl-malonyl condensing enzyme 1 (AMAC1)-1, IL-10, transforming growth factor (TGF)- $\beta$, IL-1 $\beta$, TNF $\alpha$, beta2 microglobulin $(\beta 2 \mathrm{M})$, and GAPDH (Additional File 2, Table S2) and $2 \times$ Brilliant II Sybr Green QPCR Mastermix (Stratagene, La Jolla, CA, USA). RT-PCR data were analyzed via the comparative CT $\left({ }^{\Delta \Delta} \mathrm{CT}\right)$ method [23]. Four independent cell isolations from different patient samples were used for each experiment.

\section{Generation of lentiviral particles and transduction of macrophages}

GFP-expression lentiviral particles were generated using the PACKH1 kit and 293TN cells (both SBI System Biosciences, Mountain View, CA, USA). Briefly, 293TN cells were plated in a $100 \mathrm{~mm}$ tissue culture dish (BD Falcon, Franklin Lakes, NJ, USA) in DMEM (high glucose, Invitrogen) supplemented with $10 \%$ FBS such that the cells grew to $70 \%$ confluence overnight. The medium was then replaced with DMEM (high glucose) supplemented with 1\% FCS; the plasmid mix composed to the manufacturer's instructions was added, and the cells were incubated at $37^{\circ} \mathrm{C}, 5 \% \mathrm{CO}_{2}$ in a humidified atmosphere overnight. The following day, the cell culture medium containing plasmid was removed; cells were suspended in RPMI supplemented with 10\% FCS, and passaged into a $150 \mathrm{~mm}$ tissue culture dish (BD Falcon). The virus-containing tissue culture supernatant was collected three days later, filtered $(0.45 \mu \mathrm{m}$, polyvinylidene fluoride (PVDF); Millipore, Billerica, MA, USA) to remove 293TN cells and was used immediately or stored at $-70^{\circ} \mathrm{C}$ until use. Freshly isolated macrophages were treated with $8 \mu \mathrm{g} / \mathrm{ml}$ polybrene for 10 minutes prior to the addition of virus-containing tissue culture supernatant $(1.0 \mathrm{ml}$ supernatant per $3 \mathrm{mls}$ growth medium). Cells were incubated with the supernatant for $36 \mathrm{hr}$, and then media were replaced with growth medium. Three days post-transduction, green fluorescent protein (GFP) expression was visually confirmed using a fluorescence microscope.

\section{Proliferation and invasion assays}

For all three assays, 24-hr macrophage-conditioned media were collected from macrophages cultured in 
RPMI containing $2 \%$ charcoal-stripped serum +/- estrogen $\left(10^{-10} \mathrm{M}\right)$ and used for fibroblast treatment.

Proliferation assays: primary human breast fibroblasts or immortalized human breast fibroblasts proliferating in log phase were placed in RPMI containing $2 \%$ charcoal-stripped serum (control media) for $24 \mathrm{hr}$ followed by treatment with either control media $+/$ - estrogen $\left(10^{-}\right.$ ${ }^{10} \mathrm{M}$ ) or macrophage-conditioned media treated +/estrogen, $10 \mathrm{ng} / \mathrm{ml}$ TNFa (Peprotech, Rocky Hill, NJ, USA), 1 or $10 \mu \mathrm{g} / \mathrm{ml}$ Etanercept (Immunex Corporation, Thousand Oaks, CA, USA) alone or in combination with macrophage-conditioned media treated +/- estrogen. Cells were treated for three days, then trypsinized and counted. Data represent four independent experiments with different fibroblasts and macrophage isolations used for each assay.

Invasion assays: $\mathrm{BD}$ Biocoat Matrigel invasion chambers $(8 \mu \mathrm{m}$ pores) were used according to the manufacturer's protocol (BD Biosciences, Bedford, MA, USA). Briefly, 125,000 fibroblasts were plated in serum-free media in the top chamber of transwell inserts and were allowed to invade through the membrane for up to 16 hr towards either control media $+/$ - estrogen $\left(10^{-10} \mathrm{M}\right)$, or macrophage-conditioned media, or conditioned media from macrophages treated with estrogen in the bottom chamber. Following invasion, the cells were wiped from the top surface of the membrane; the remaining cells were fixed in methanol and stained with a $1 \%$ toluidine blue solution. Five independent experiments, each with different patient samples (fibroblasts and macrophage conditioned media) were performed with each individual experiment plated in triplicate to ensure repeatability. Cells were imaged and quantified using NIH Image J 64 software.

For MMP inhibitor invasion studies, 20 or $100 \mathrm{nM}$ MMP9 inhibitor (Calbiochem, Gibbstown, NJ, USA) were added to the top chamber of transwell inserts at the time of plating.

\section{Quantitative multiplex cytokine and chemokine ELISA assays}

A multiplex ELISA kit (Quansys Biosciences, Logan, UT, USA) was used to quantify a panel of 16 cytokines (IL$1 \alpha$, IL-1 $\beta$, IL-2, IL-4, IL-5, IL-6, IL-10, IL-12p70, IL-13, IL-15, IL-17, IL-23, IFN- $\gamma$, TNF $\alpha$ and TNF $\beta$ ) and 16 chemokines (Eotaxin, GROa, I-309, IL-8, IP-10, monocyte chemoattractant protein (MCP)-1 and -2 , regulated on-activation normal $\mathrm{T}$ cells expressed and excreted (RANTES), thymus and activation-regulated chemokine (TARC), angiopoietin (ANG)-2, basic fibroblasts growth factors (bFGF), hepatocyte growth factor (HGF), platelet derived growth factor (PDGF)-BB, tissue inhibitor of metalloproteinase (TIMP)-1 and -2 , and vascular endothelial growth factor (VEGF) from conditioned media according to the manufacturer's protocol.

\section{Zymography and western analysis}

Conditioned media were collected, concentrated using Amicon Ultra centrifugation filter (MWCO 10K, Millipore), and protein concentrations was determined by Bradford assay (Thermo Scientific; Rockford, IL) according to the manufacturer's instructions.

Zymography: Gelatin zymography was performed using pre-cast $10 \%$ Zymogen $0.1 \%$ gelatin gels (Invitrogen) according to the manufacturer's instructions. MMP activity was visualized as clear bands against a dark blue background using SimplyBlue SafeStain (Invitrogen) where the protease has digested the substrate. Identification of MMPs was based on the migration pattern of pro- and activated MMP proteins similarly separated, as well as by their published molecular weights.

Western blotting: equal concentrations of conditioned media, as determined by the Bradford assay, were separated by SDS-PAGE under reducing conditions. Membranes were blocked in 5\% non-fat milk for $1 \mathrm{hr}$ at room temperature, incubated with primary antibody (MMP9, MMP2; Abcam) overnight at $4^{\circ} \mathrm{C}$, washed, and incubated with the appropriate secondary antibody conjugated to horseradish peroxidase (GE Healthcare, Piscataway, NJ, USA). Peroxidase activity was detected using the enhanced chemiluminescence detection system (ECL Plus, GE Healthcare) according to the manufacturer's recommendations. Four independent experiments, each with different patient samples for each cell type with each individual experiment repeated in duplicate, were performed to ensure repeatability for each assay.

\section{Immunohistochemistry}

Immunohistochemistry was performed with appropriate controls as described previously [24]. Briefly, $5 \mu \mathrm{m}$ thick sections of formalin fixed, paraffin embedded tissue were prepared from humanized glands. The human specific CD14 antibody (1:200, Sigma) was used to detect human monocytes/macrophages in humanized glands, the human-specific proliferating cell nuclear antigen (PCNA) antibody (AbCam ab53048) was used to detect proliferating human fibroblast in the mammary gland, and the human-specific MMP antibody (1:200 Abcam AB76003) was used to detect human cell-derived MMP9. Histosections were pretreated with Dako Target Retrieval solution and stained using Vectastain ABC kit (Vector Laboratories; Burlingame, CA, USA) according to the manufacturer's instructions. Color was developed with diaminobenzidine peroxidase substrate kit (Vector Laboratories) and sections were counterstained with 
hematoxylin. A minimum of five glands per treatment group was analyzed for each assay.

\section{Image quantitation}

For determination of the percent of gland humanized, H\&E-stained sections of each gland were imaged with the Zeiss SteREO Discovery V12 microscope. Total and humanized areas were determined by histological examination, measured using the freehand outline tool, and calculated using Axiovision V4.8 software. Cell invasion was imaged using an Olympus IX51 microscope at 20x magnification and quantified using NIH Image J software (threshold-standardized; measurement determined as percent area: red).

\section{Statistical analysis}

Data were evaluated for significance using $t$-tests or one-way analysis of variance (ANOVA) with the appropriate post hoc analysis (Tukey, Bonferroni) using GraphPad InStat Software version 3.0b (San Diego, CA, USA). Data were considered significant at $P<0.05$.

\section{Results}

Murine mammary gland humanization is significantly enhanced with macrophages and ectopic estrogen stimulation

Macrophages perform a vital role in mammary development and function [7]; therefore, we hypothesized that the introduction of human macrophages would enhance humanization of the murine mammary gland. Moreover, the addition of macrophages would permit an intimate look at human immune and stromal-derived paracrine cell interactions in a dynamic in vivo model.

The standard humanization procedure does not require ectopic estrogen hormonal stimulation for ductal development of the human epithelial cells as long as the procedure is performed prior to the end of puberty [6]. However, circulating estrogen levels in the mouse are lower compared to circulating levels in premenopausal women, and are essentially comparable to levels found in postmenopausal women [25]. Additionally, macrophages have estrogen receptors [26,27], and estrogens are known to influence the maturation and function of macrophages, as well as to have suppressive effects on the expression of cytokines and other inflammatory modulators [27]. Thus, as the fibroblasts and macrophages used in this study were obtained from premenopausal women, and it is unknown what contributing factor estrogens have on mammary macrophage function in this assay, the effects of ectopic estrogen stimulation in the humanization procedure were also investigated.

Both primary breast fibroblasts and peripheral blood monocytes/macrophages were isolated from premenopausal women. It was taken care that additional, contaminating immune cells were removed via cell culture selection through monocyte and macrophage adherence to plastic. To ensure purity and to obtain a more homogeneous cell population, cells were further differentiated into macrophages by IFN $\gamma$ and LPS treatment. Additional File 3, Figure S1A shows cells immediately post-isolation and three days post differentiation treatment. Treatment induced a predominately classic activation of macrophage differentiation, as determined by quantitative RT-PCR of genes associated with the classical and alternative activation status of macrophages (Additional File 3, Figure S1B). A comparison of treatment with CSF-1 (100 ng/ml) and IFN $\gamma / \mathrm{LPS}$ was performed as reports suggest that differentiation with CSF-1 in mammary tissue may differentially influence macrophage phenotype. Of the 43 macrophage differentiation and polarization genes analyzed, only four genes were significantly differentially expressed (Additional File 1, Table S1, $P<0.05$; BIRC3, CCR7, CD163, and $P T X 3)$, suggesting no substantial difference between differentiation protocols.

In order to study the effect of macrophages and estrogen on mammary gland engraftment and outgrowth in a humanized mouse model of the mammary gland, we cleared the mammary fat pad, injected fibroblasts and macrophages in the presence or absence of ectopic estrogen, and allowed engraftment of the fat pad with these human stromal cells. Two weeks post-humanization, primary breast epithelial cells/organoids and additional fibroblasts were injected into the glands [6] with or without the addition of macrophages corresponding to the initial injections (Figure 1A).

The percent of gland humanized was calculated by histological examination of the identified humanized regions followed by measurement of the total and humanized areas using Axiovision V4.8 software (Figure 1B). In agreement with the standard protocol, the fibroblasts outgrowths and epithelial acini-like structures within the fibroblasts were readily detected in the murine mammary tissue for all treatments tested (Figure 1C). FISH analysis determined that the cellular outgrowths measured/observed were of human origin (Figure 1D). The combined treatment of macrophages and ectopic estrogen stimulation significantly enhanced the percentage of the total gland humanized (Figure $1 \mathrm{E}, \mathrm{P}<$ $0.05)$ as well as enhanced the success rate of engraftment and outgrowth ( $45 \%$ vs. $70 \%$ glands displaying outgrowths, data not shown). The glands humanized with either macrophages or ectopic estrogen treatment alone exhibited a trend to larger humanized outgrowths compared to the standard humanization protocol. Overall these data suggest that both the percent of the gland humanized as well as the engraftment rate was 


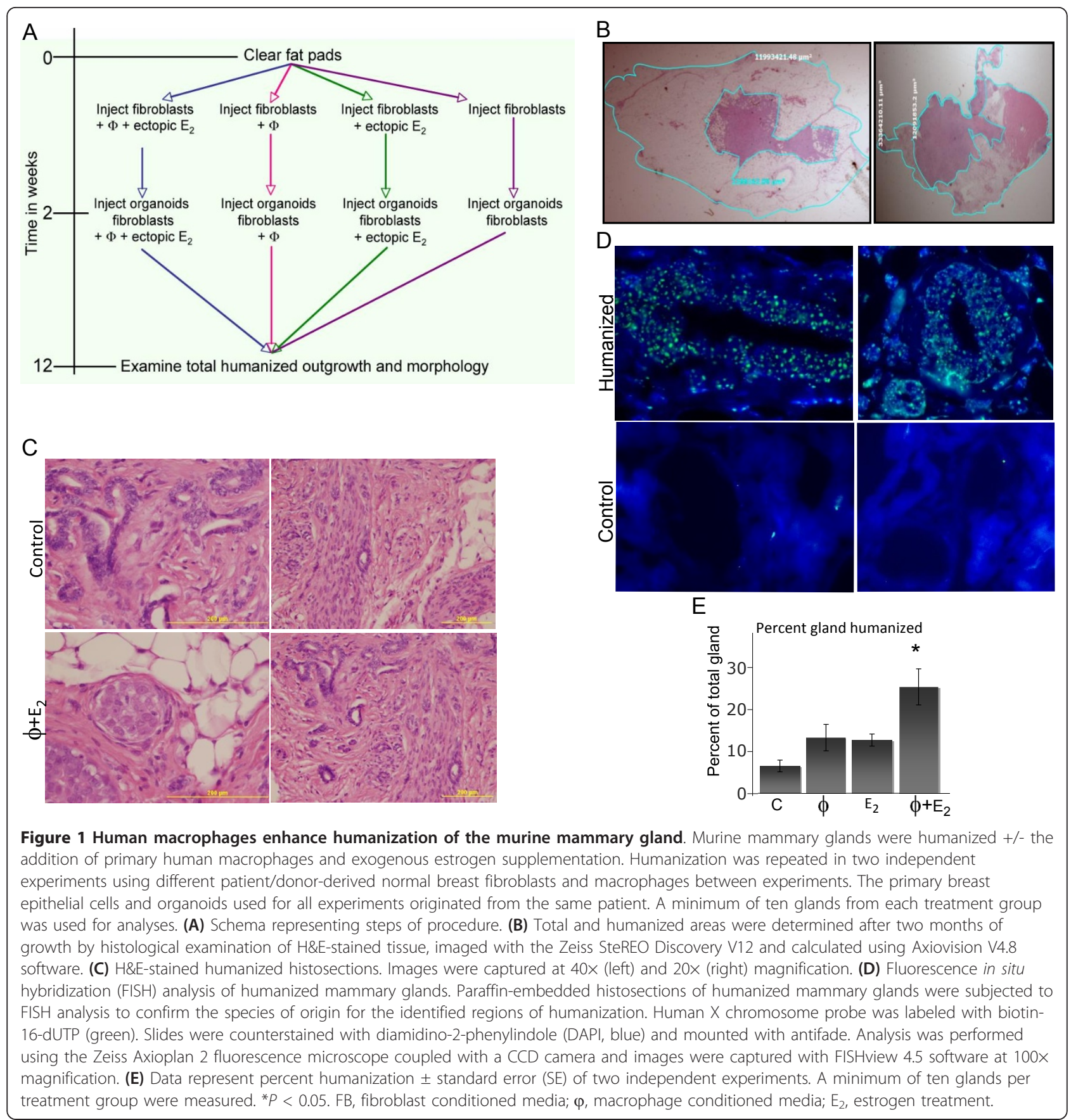

significantly enhanced by the combined addition of macrophages and ectopic estrogen supplementation.

\section{Transitory macrophages enhance fibroblast outgrowth during early stages of humanization}

Having demonstrated enhanced engraftment and humanization of the mouse mammary fat pad by exposure to estrogen and human macrophage injection, without observing an altered histology of the humanized areas between different treatment groups, we next asked if a combined macrophage/estrogen treatment might influence overall cellular growth or enhance the invasiveness of human fibroblasts.

Immunohistochemistry using a human-specific CD14 antibody revealed that no human macrophages were present at the time of gland collection (two months post-final injection of cells, data not shown). Therefore, we examined the timing of the disappearance of the human macrophages from the gland using freshly isolated macrophages transduced with lentiviral particles to 


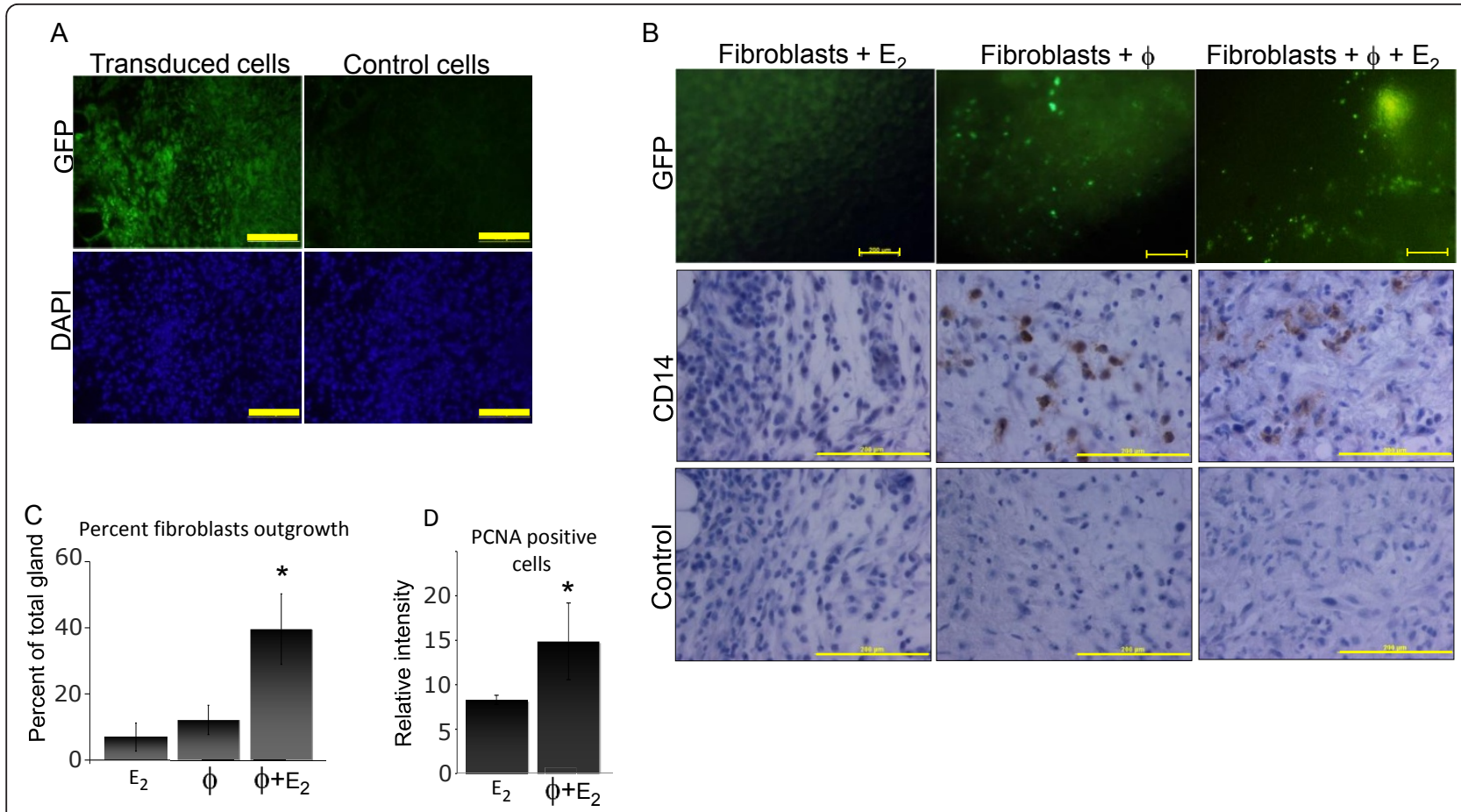

Figure 2 Transitory macrophages enhance early states of fibroblast outgrowth during humanization. (A) Primary human monocytes/ macrophages were isolated via Ficoll separation from apheresis product, differentiated, and then transduced with green fluorescent protein (GFP). Images show cells $48 \mathrm{hr}$ post-transduction with GFP or negative controls. Cell nuclei were stained with diamidino-2-phenylindole (DAPI) for visualization (blue, bottom panels). (B) Primary breast fibroblasts were injected with or without the GFP-expressing macrophages in the presence or absence of ectopic estrogen. Six days post-injection freshly excised glands were imaged using a GFP filter. Immunohistochemical detection of human macrophages (day six) humanized glands using a human-specific CD14 antibody (top panels) or corresponding negative controls (bottom panels; scale bar $=200 \mu \mathrm{m}$ ). (C) Percent gland humanized after ten days of fibroblast growth $+/$ - estrogen $+/$ - macrophages. Total and humanized areas were determined by histological examination, imaged with the Zeiss SteREO Discovery V12 and calculated using Axiovision V4.8 software. Data represent percent humanization \pm SD. Four glands per treatment group were measured. ${ }^{*} P<0.01$. (D) Tissues were subjected to immunohistochemical analysis with a proliferating cell nuclear antigen (PCNA) antibody to identify proliferative cells. Stained histosections were imaged and quantified using NIH Image J software. Data represent average of four counts per gland \pm SD. Three glands per treatment group were measured. ${ }^{*} P<0.02$.

induce expression of GFP (Figure 2A). Glands were humanized and collected 2, 6, 10 and 40 days post-injection. Presence of macrophages was measured by three methods: immunofluorescent detection of GFP immediately following excision of the glands, immunohistochemical detection using a human-specific CD14 antibody on paraffin-embedded histosections, and RTPCR of RNA isolated from the glands using human specific primers to CD14 and CD68.

Macrophages were readily detected two days postinjection by all three methods. RT-PCR analysis showed a decrease of human CD14- and CD68-mRNA between day 2 and day 6 after injection of human macrophages into the mammary fat pad (Table 1). Human CD14 and human CD68 were no longer detectable 10 days after injection of macrophages; GFP-labeled human macrophages were also readily detected in the mammary fat pad 2 days and 6 days after inoculation with GFPlabeled macrophages (Figure 2A, B). Likewise, we demonstrated the presence of human macrophages in the mammary fat pad 6 days after inoculation by immunohistochemistry for human CD14 (Figure 2B). At days 24 and 40, all methods confirmed the lack of human macrophages within the humanized gland (data not shown). Taken together, these data demonstrate that human macrophages are only temporarily present in the inoculated mammary fat pad. This indicates a transient interaction of macrophages, fibroblasts, and the stroma of the mammary fat pad during the first stage of mammary fat pad humanization, which subsequently enhances future engraftment with human breast epithelial cells.

To test this hypothesis, glands were humanized with fibroblasts and ectopic estrogen, with fibroblasts and macrophages, or with a combination of all three to evaluate the initial step of humanization, the outgrowth of fibroblasts into the murine mammary fat pad. After ten days of growth, the glands were harvested as in the 
Table 1 Time course of real time-PCR detection of human macrophages in humanized glands

\begin{tabular}{|c|c|c|c|c|c|c|}
\hline & CD14 & SD & CD68 & SD & GAPDH & SD \\
\hline \multicolumn{7}{|l|}{ Day 2} \\
\hline$+E_{2}$ & No CT & & No CT & & 22.28 & 0.26 \\
\hline + Macrophages & 23.88 & 0.10 & 28.18 & 0.24 & 21.59 & 0.24 \\
\hline$+E_{2}$ and Macrophages & 26.36 & 0.16 & 28.52 & 1.50 & 22.69 & 0.23 \\
\hline \multicolumn{7}{|l|}{ Day 6} \\
\hline$+E_{2}$ & No $C T$ & & No $C T$ & & 22.48 & 0.31 \\
\hline + Macrophages & 28.37 & 3.40 & $30.02^{a}$ & 1.39 & 20.88 & 0.70 \\
\hline$+E_{2}$ and Macrophages & 27.65 & 4.92 & $30.01^{a}$ & 3.57 & 19.69 & 0.91 \\
\hline \multicolumn{7}{|l|}{ Day 10} \\
\hline$+E_{2}$ & No CT & & No CT & & 19.16 & 0.33 \\
\hline + Macrophages & $31.05^{\mathrm{a}}$ & 0.81 & $30.81^{a}$ & 1.55 & 18.51 & 0.15 \\
\hline$+E_{2}$ and Macrophages & 29.43 & 1.51 & $31.28^{a}$ & 1.12 & 18.65 & 1.13 \\
\hline \multicolumn{7}{|l|}{ Controls } \\
\hline Human monocytes & 14.4 & 0.14 & 16.3 & 0.16 & 20.59 & 0.07 \\
\hline Human macrophages & 16.5 & 0.16 & 20.2 & 0.09 & 21.00 & 0.20 \\
\hline Murine mammary gland & No $C T$ & & No $C T$ & & 21.45 & 0.14 \\
\hline
\end{tabular}

${ }^{a}$ Cycle Threshold (CT) values over 30 were not considered positive for a detectable signal. Analysis was terminated at 32 cycles. $E_{2}$, ectopic estradiol treatment; GAPDH, glyceraldehyde-3-phosphate dehydrogenase.

standard protocol for the initial humanization step. As shown in Figure 2C, the combination of treatments significantly enhanced fibroblast growth throughout the gland compared to the addition of macrophages or ectopic estrogen alone $(P<0.01)$. These data suggest that the enhanced humanization is due to an increase in the overall area of human stromal outgrowth, thereby providing a larger humanized area for acini proliferation and outgrowth. Indeed, immunohistochemistry revealed significant increase of PCNA-positive, proliferating fibroblasts in glands humanized with macrophages compared to fibroblasts alone (Figure 2D, $\mathrm{P}<0.02$ ).

Collectively, these data indicate that the stimulatory mechanisms of the macrophages on humanization are transitory, as the macrophages disappear from the murine gland within 10 days post-injection. However, our data indicate that their presence at the time of injection, and within a week thereafter, has a significant and long lasting effect on mouse mammary gland humanization with human fibroblasts and consecutive engraftment with human mammary epithelial cells. The increased proliferation of human fibroblasts might be a relevant mechanism for the observed increased humanization of the mouse mammary fat pad.

\section{Macrophages enhance fibroblast proliferation, in part, through a TNF $\alpha$ dependent mechanism}

We determined that paracrine interactions between primary macrophages and fibroblasts enhance humanization of the gland. To identify potential mechanisms by which the macrophages enhanced humanization, four different in vitro cell proliferation assays were used to determine if (1) direct cell-to-cell contact was necessary between the fibroblasts and macrophages, or (2) if secreted factors from the macrophages were sufficient to induce fibroblasts proliferation, and (3) whether estrogen enhanced these effects. Fibroblasts were either cocultured directly with macrophages in the presence or absence of estrogen treatment, cultured in the presence of the macrophages but separated from physical contact with a transwell insert, treated with macrophage-conditioned media, or treated with co-conditioned media from fibroblast and macrophage direct co-cultures (Additional File 4, Figure S2). Overall, when fibroblasts were cultured in the presence of the estrogen-treated macrophage-conditioned media, cell proliferation was equivalent or greater than any other treatment condition. Based on these initial results, we more rigorously examined the effects of macrophage-conditioned media in the presence or absence of estrogen treatment using seven freshly isolated individual fibroblasts patient samples each treated with the conditioned media from three different macrophage patient samples (Figure 3). These data confirm the original observation that fibroblasts cultured in the presence of the estrogen-treated macrophage-conditioned media exhibit significantly enhanced cell proliferation compared to control or estrogen treatment $(P<0.01)$.

To identify macrophage-specific secreted factors responsible for the increase in fibroblast proliferation,

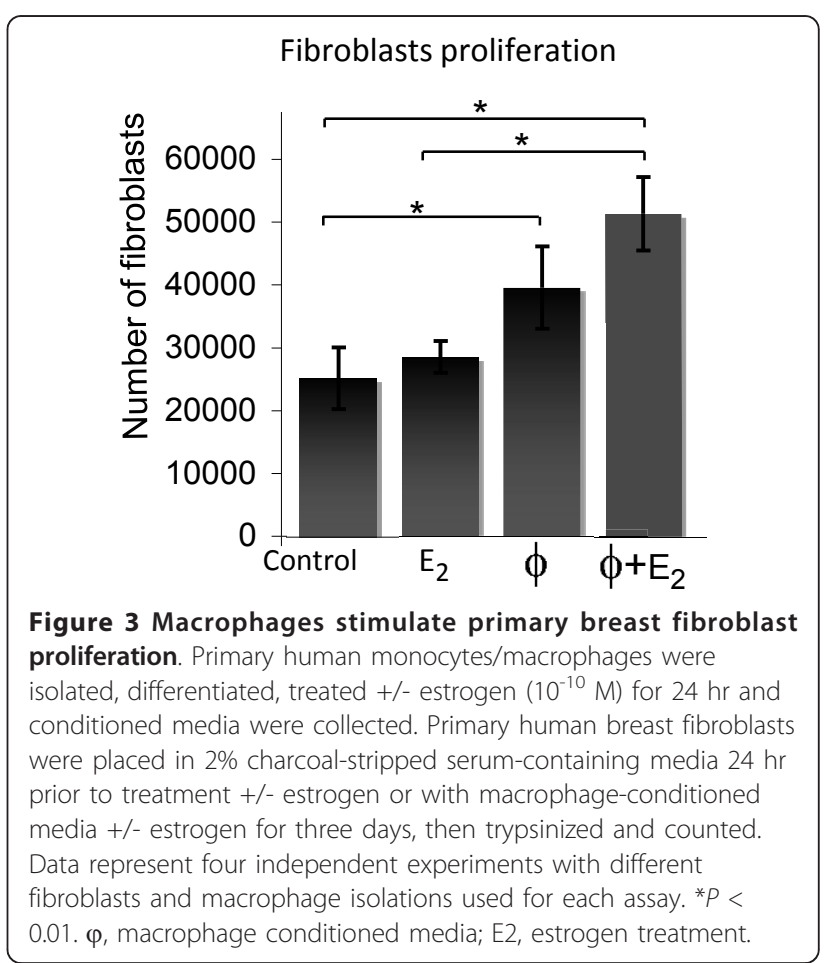


quantitative multiplex cytokine and chemokine ELISAbased assays were performed. Three independent monocyte/macrophage isolations were prepared, followed by differentiation and treatment for $24 \mathrm{hr}$ in the presence or absence of estrogen. Half of the macrophage-conditioned media were immediately frozen and stored for analysis, and half were placed on fibroblast cultures for $24 \mathrm{hr}$ to obtain co-conditioned media. Each of the three macrophage conditioned media samples were used to treat a minimum of two independent breast fibroblast isolations and the co-conditioned media were collected from each individual fibroblast sample. One striking observation was a significant decrease in TNF $\alpha$ after macrophage-conditioned media was used to treat the fibroblasts (mean $\pm \mathrm{SD}, 60.9 \pm 1.1 \mathrm{pg} / \mathrm{ml}$ vs. $17.6 \pm 2.8$ $\mathrm{pg} / \mathrm{ml}$, respectively; $P<0.001)$, potentially suggesting cellular uptake. TNF $\alpha$ has been reported to stimulate dermal and foreskin fibroblast chemotaxis and proliferation in vitro and in vivo [28-30]; therefore, we tested the ability of the macrophage-derived TNF $\alpha$ to stimulate breast fibroblast proliferation. Initial studies were performed using hTERT immortalized breast fibroblasts [6] to determine whether breast fibroblasts proliferate in response to TNF $\alpha$ stimulation, and to optimize the concentration of TNFa inhibitor (Etanercept) (data not shown). Immortalized and primary breast fibroblasts were then treated with estrogen-stimulated macrophageconditioned media or TNF $\alpha(10 \mathrm{ng} / \mathrm{ml})$ in the presence or absence of the TNF $\alpha$ inhibitor $(10 \mu \mathrm{g} / \mathrm{ml})$. As shown in Figure $4 \mathrm{~A}$ and $4 \mathrm{~B}$, the proliferation of breast fibroblasts treated with estrogen-stimulated macrophage-conditioned media was significantly inhibited in the presence of the TNF $\alpha$ inhibitor $(P<0.05)$. Macrophageconditioned media enhanced fibroblast proliferation more than TNF $\alpha$ alone (Figure 4B), suggesting that other factors also contributed to cell proliferation; however, our data demonstrate that enhanced proliferation occurs, in part, through a TNF $\alpha$ dependent mechanism.

\section{Macrophages stimulate enhanced fibroblast invasion through upregulation of MMP-9 activity}

During humanization, the fibroblasts injected into the gland must proliferate as well as migrate throughout the gland, which requires the active degradation of the basement membrane and extracellular matrix of the murine gland. Having already determined that macrophages enhanced fibroblast proliferation, we next investigated whether stimulation by macrophages, estrogen, or the combination, enhanced fibroblast invasion as well. Primary human breast fibroblasts were subjected to transwell Matrigel invasion assays using either control or macrophage-conditioned media containing $2 \%$ charcoalstripped serum +/- estrogen $\left(10^{-10} \mathrm{M}\right)$ as chemoattractants. Twenty-four hours post-seeding, invaded cells were stained with toluidine blue, imaged, and quantified (Figure 5A). Results from five independent experiments using different fibroblast and macrophage isolations for each assay demonstrated that both macrophage-conditioned media and estrogen-stimulated macrophage-conditioned media significantly increase fibroblast invasion above controls (Figure $5 \mathrm{~B}, \mathrm{P}<0.01$ ). Estrogen alone enhanced fibroblast invasion, but the increase was not significant. These data demonstrate that chemokines and additional molecules secreted from the macrophages enhance extracellular matrix degradation and fibroblasts invasion, potentially replicating another mechanism by which macrophages enhance humanization in vivo. These results were similar to those obtained in the in

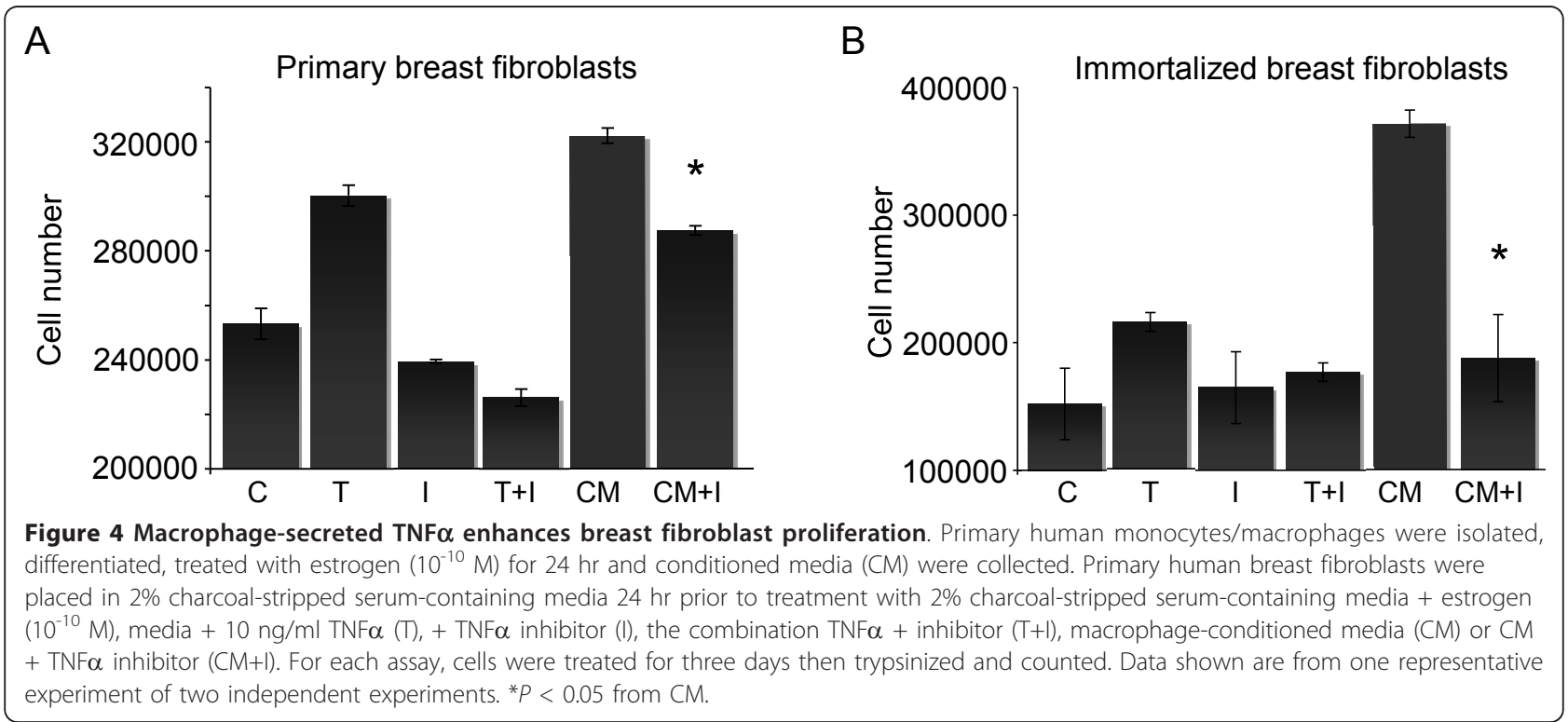




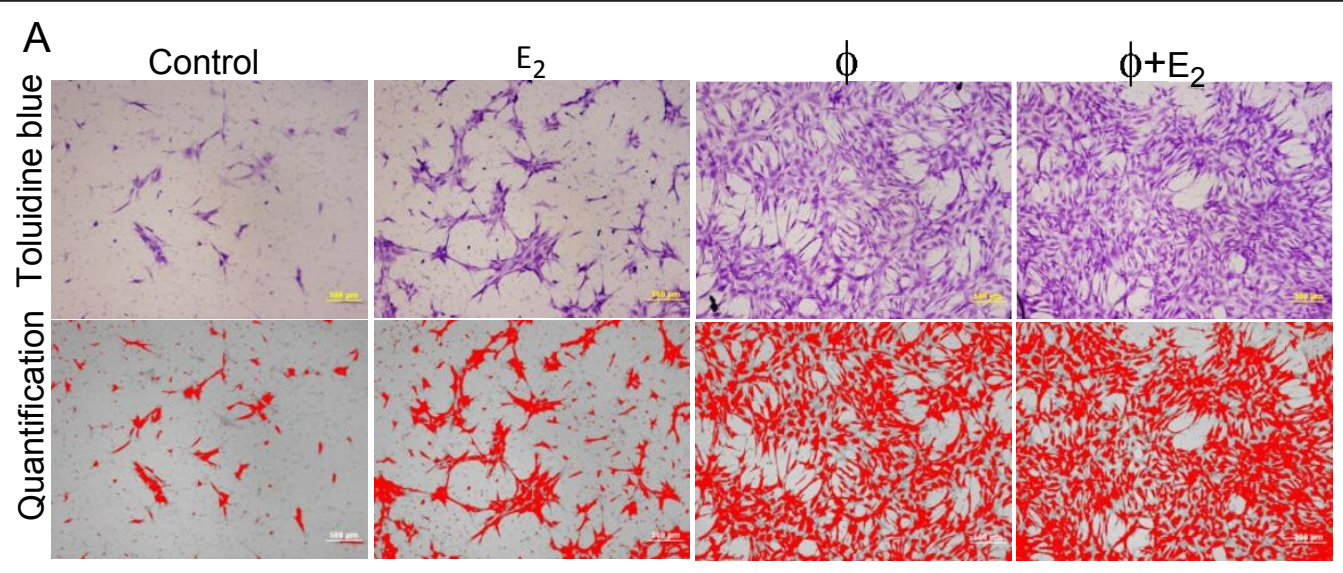

B

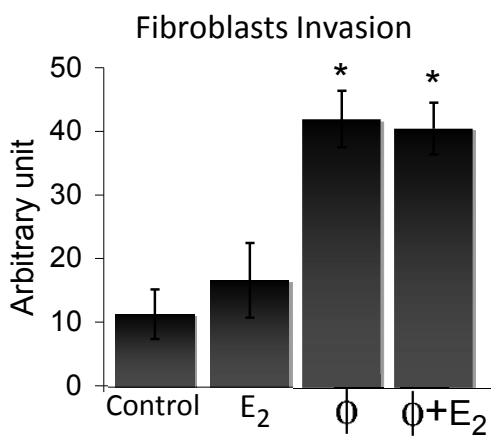

Figure 5 Enhanced primary breast fibroblast invasion in the presence of human macrophages conditioned media. Primary human macrophages were treated $+/$ - estrogen $\left(10^{-10} \mathrm{M}\right)$ in $2 \%$ charcoal-stripped serum-containing media and 24 hr-conditioned media were collected. Primary human breast fibroblasts were seeded in serum-free media into Matrigel invasions chambers in triplicate. Chemoattractants were $2 \%$ charcoal-stripped serum (control), control media + estrogen $\left(10^{-10} \mathrm{M}\right)$, macrophage-conditioned media, or conditioned media from macrophages treated with estrogen. (A) $24 \mathrm{hr}$ post-seeding, invaded cells were stained with toluidine blue (top panels), imaged and quantified using $\mathrm{NIH}$ Image J software (measurement highlighted in red, bottom panels). (B) Data represent average area measurement of invaded cells $+/$ - standard error (SE) of five independent experiments. ${ }^{*} P<0.01$ above control or $E_{2}$ treatment. $\varphi$, macrophage conditioned media; $E_{2}$, estrogen treatment.

vitro proliferation assays; either macrophages alone or estrogen-stimulated macrophages were able to significantly enhance fibroblast behavior. In contrast to these in vitro measurements of cell behavior, ectopic estrogen stimulation is required to obtain the most significant amount of humanization in vivo.

Given the known role of matrix metalloproteinases (MMPs) in cell invasion and mammary development $[31,32]$, we hypothesized that upregulation of MMPs was one mechanism by which macrophages enhanced fibroblasts invasion and thus overall humanization. Gelatin zymography and western blot analyses were used to evaluate the levels and activity of MMPs from the conditioned media of either fibroblasts alone or stimulated with macrophage-conditioned media. Membranes were stained with Ponceau $\mathrm{S}$ to ensure equal loading of protein (Additional File 5, Figure S3). Four independent experiments, each with different patient samples for each cell type with each individual experiment repeated in duplicate, were performed to ensure reproducibility for each assay. Results demonstrate that fibroblasts treated with macrophage-conditioned media had significantly increased MMP9 activity and expression (Figure 6A, B) while MMP2 levels remained relatively unchanged regardless of treatment. An additional increase in MMP9 activity and levels in the conditioned media of fibroblasts treated with the estrogen stimulated macrophage-conditioned media was also observed (Figure 6A, B; quantification in Additional File 5, Figure S3).

To confirm our in vitro findings, the levels of MMP9 during early stages of humanization were examined. Paraffin-embedded sections of glands humanized with fibroblasts and ectopic estrogen or fibroblasts with primary human macrophages and ectopic estrogen were collected 2, 6 (Figure 6C), and 10 days post-injection and analyzed immunohistochemically using a humanspecific MMP9 antibody. Analysis at each time point 


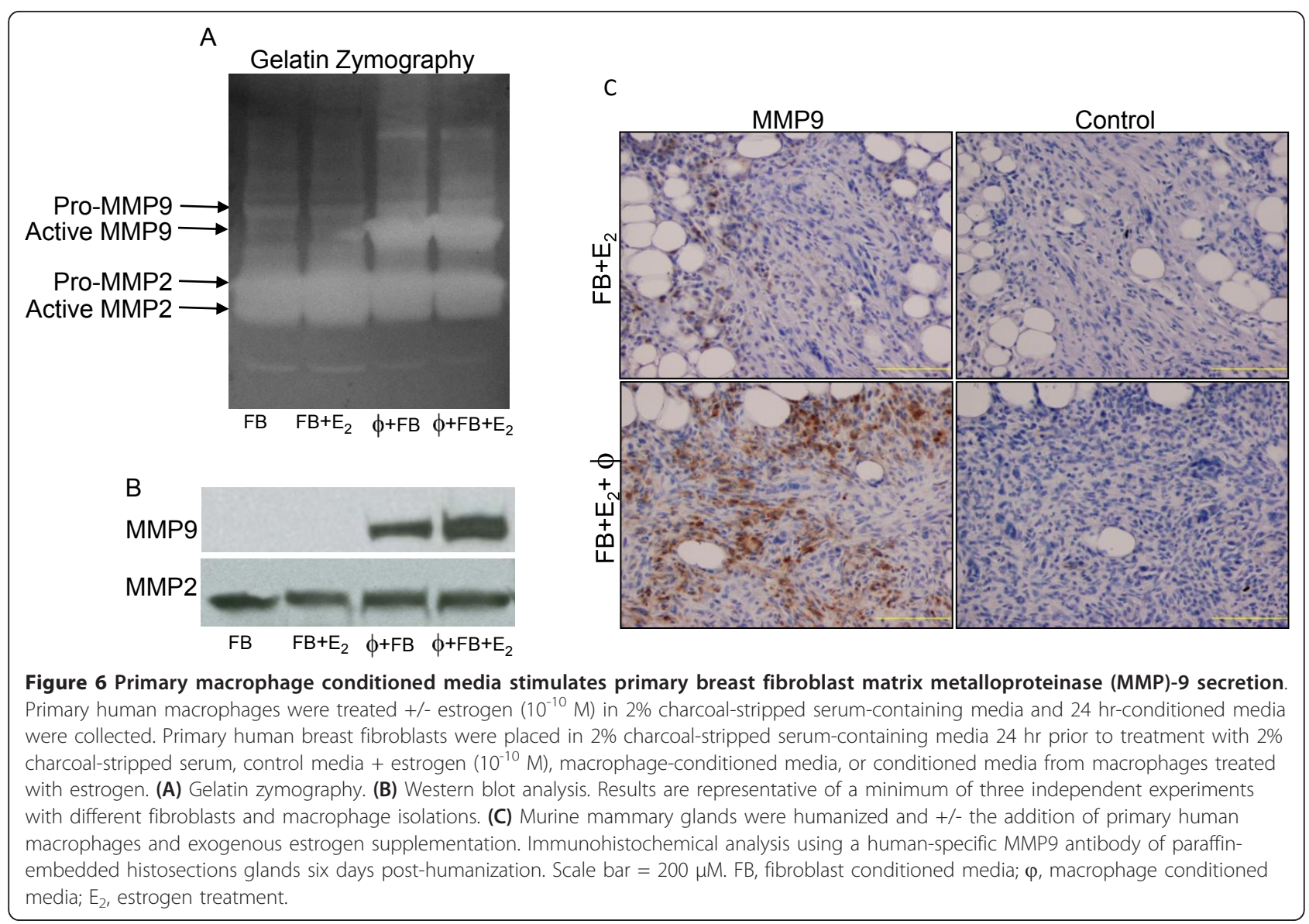

expressed significantly higher levels of MMP9 in the humanized regions of the gland, similar to results from zymography and western analyses, demonstrating an increase in MMP9 when macrophages are present.

To further support our hypothesis that increased activity of MMPs enhances humanization, we performed additional assays investigating the ability of macrophagestimulated MMP9 activity to increase fibroblast invasion. Primary and immortalized human breast fibroblasts were again subjected to transwell Matrigel invasion assays using estrogen-stimulated macrophage-conditioned media as the chemoattractant; however, a specific MMP9 inhibitor was added to the fibroblasts when plated in the transwell chamber. Invaded cells were stained with toluidine blue $24 \mathrm{hr}$ post-seeding, imaged, and quantified (Figure 7A). Results from two independent experiments using different fibroblasts and macrophage isolations for each assay demonstrated that inhibition of MMP9 activity decreased fibroblast invasion in a dosedependent manner (Figure 7B, $\mathrm{P}<0.01$ ). However, it is noted that in these in vitro studies it is not possible to distinguish chemotaxis from chemokinesis. Collectively, our results demonstrate that macrophage-stimulated enhanced humanization is due in part, to increased
MMP9 degradation of extracellular matrix, thereby facilitating fibroblast invasion throughout the gland.

\section{Macrophages stimulate enhanced tumor formation in humanized glands}

Previous studies show that the source of stromal fibroblast can significantly affect epithelial cell morphology and proliferation, as well as tumor engraftment and aspects of behavior [6,33-39]. Therefore, an initial study was performed to observe the effect of macrophages on breast cancer cell engraftment of humanized glands. This experiment is one initial experiment, used only to support the need for future tumorigenesis studies using this model. The right abdominal gland was humanized in the presence or absence of estrogen-stimulated macrophages, and mice were supplemented with subcutaneous estrogen pellets (five mice were injected in the control group and five mice in the treatment group). Two weeks post-humanization, $1 \times 10^{6}$ T47D breast cancer cells were injected with fibroblasts or fibroblasts and macrophages into the humanized region. As shown in Figure 8, the glands humanized with macrophages had enhanced engraftment rate and tumor growth compared to the glands humanized with fibroblasts alone 


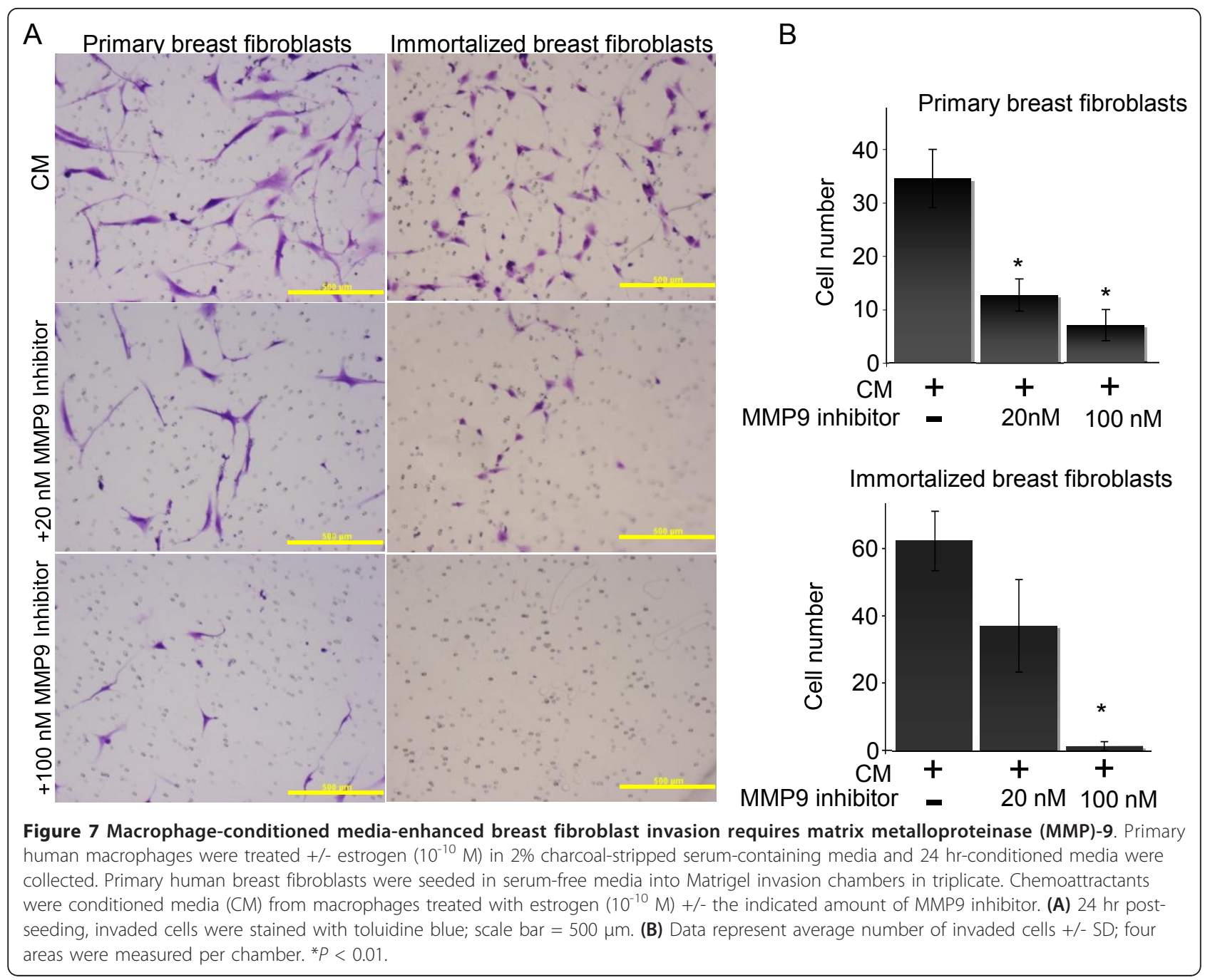

(one tumor in the standard humanized glands out of five injected mice vs. three tumors out of five mice in the macrophage group). Initial studies show no overt differences in tumor morphology between treatment groups and additional studies are under investigation. Similar to humanized studies, no human macrophages were detected in the xenograft tumors or surrounding tissues at the time of collection.

\section{Discussion}

This study demonstrates that intricate, temporary, stroma-derived paracrine cell interactions in a humanized in vivo model system can improve engraftment of the mammary fat pad. Based on the heterogeneic mouse model of the human mammary gland developed by Kuperwasser et al. [6] we expanded upon the model by incorporating human immune cells, in addition to human fibroblasts, to investigate multi-cellular primary human cell interactions in vivo. The addition of macrophages enhanced humanization of the gland by augmenting fibroblast proliferation and invasion throughout the gland, thereby providing a larger stromal bed for human breast epithelial cell proliferation and formation of acini and ductal structures. We have identified two specific paracrine mechanisms involved in enhancement of humanization: increased fibroblast proliferation stimulated by macrophage-derived TNF $\alpha$ as well as a macrophage-stimulated increase in MMP9 expression and proteinase activity. Our observed in vivo results have been confirmed with in vitro studies, again highlighting the value of this model to interchangeably support in vitro and in vivo results.

It is of note that no gross morphologic differences were observed within the epithelial structures of the macrophage- and estrogen-stimulated humanized outgrowths compared to the standard protocol (Figure 1C). However, one should note that in the present study we did not investigate epithelial function or differentiation 


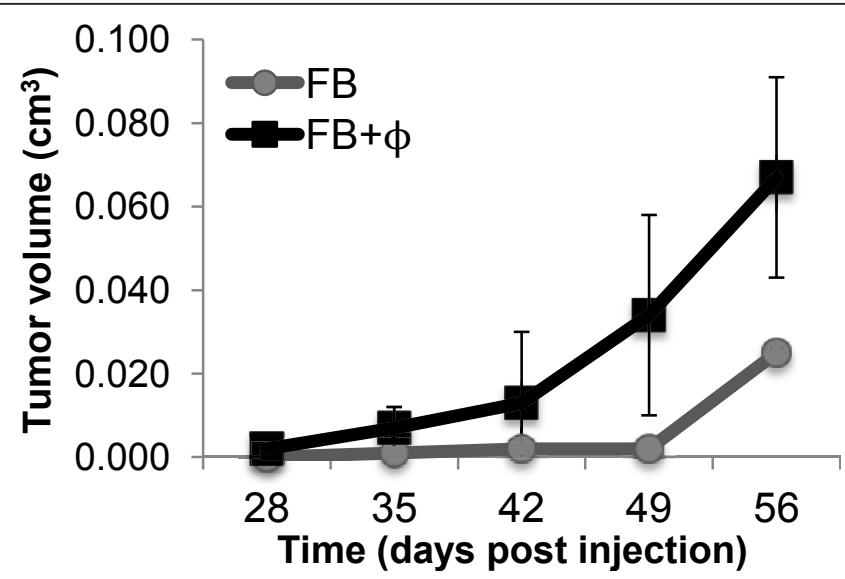

Figure 8 Macrophages enhanced tumor growth of humanized glands. Murine mammary glands were humanized $+/-$ the addition of primary human macrophages and exogenous estrogen supplementation ( 5 mice per treatment group). Two weeks post-humanization, $1 \times 10^{6}$ T47D breast cancer cells were injected with fibroblasts or fibroblasts and macrophages into the humanized region. One tumor out of a total of five injected mice developed tumors in the standard humanized treatment group, while three tumors out of five injected mice developed tumors in the glands humanized with macrophages. Data represent mean +/- SD.

during pregnancy and lactation. The critical role macrophages play in orchestrating these important developmental stages of the mammary gland is continually emerging [9,40-42]; future experiments using this in vivo model to further observe macrophage function during pregnancy and lactation will be an interesting avenue to explore. The activation stage of macrophages has recently been reported to have a unique function during different stages of mammary gland differentiation [43] and has been shown to differentially influence breast cancer cell behavior [44]. This model system enables novel, in vivo studies investigating the role of human macrophages in normal breast, as well as in breast cancer xenograft studies. However, it should be noted that the addition of macrophages may not have an effect on epithelial cell differentiation, as the introduction of M1type macrophages may have created more of an initial wound healing microenvironment, resulting in improved human fibroblast engraftment during the resolution phase when human macrophages are no longer present.

In the present study, peripheral blood monocytes isolated from premenopausal women were differentiated using the classical method of adherence to plastic followed by treatment with LPS and IFN $\gamma[45,46]$. IFN $\gamma$ is an immunostimulatory cytokine that primes monocytes for differentiation in response to LPS [47]. This method was chosen as it produced a more homogeneous population of macrophages as compared to other differentiation methods, and the macrophages produced higher amounts of proinflammatory cytokines compared to alternatively activated macrophages (Additional File 1, Figure S1). Although limited data exist on the role of proinflammatory cytokines in the human breast, IFN $\gamma$ has been reported to be present in the breast during development and milk production [48]. In vitro studies have shown that human mammary epithelial cells contain the IFN $\gamma$ receptor and are sensitive to IFN- $\gamma$ stimulation, resulting in inhibition of proliferation, disruption of cell polarity and tight junctions; all are critical steps in milk stasis, involution and tissue remodeling during outgrowth [49-51]. Therefore, the presence of IFN $\gamma$ during stages of breast tissue remodeling suggests the potential for monocyte/macrophage exposure in breast tissue, and a role for IFN- $\gamma$ in breast function. However, many of the studies defining the role of mammary macrophages have focused on the role of CSF-1, which regulates macrophage behavior, morphology and motility and, through a series of eloquent genetic mousemodel experiments, has been shown to be critical for mammary gland development and function $[52,53]$. Gyorki et al. (2009) demonstrated that mammary macrophages contribute to normal stem/progenitor cell function in the developing mouse mammary gland, using both the $C_{s f} 1^{\mathrm{op} / \mathrm{op}}$ mice and the clondronate-containing liposomes ablation method [54]. They suggest that mammary stem cells require macrophage-derived factors to be fully functional. Our data show that in vitro treatment of the cells with either CSF-1 or LPS/ IFN $\gamma$ has no significant effect on 39 of the 43 differentiation and polarization genes analyzed (Additional File 1, Table S1), suggesting no substantial difference between differentiation protocols. However, the possibility exists that upon introduction to the mouse mammary fat pad, the local and systemic factors had an additional influence on the human macrophages phenotype. Given the wealth of data on CSF-1 in the 
developing gland, it would be of interest to observe the effect of CSF-1-differentiated human macrophages on humanization of the mammary fat pad.

In the present study, it is not known whether the macrophages stimulated a wound-healing response or other developmental processes to enhance humanization of the mouse fat pad. The LPS/IFN- $\gamma$-stimulated macrophages exhibited increased proinflammatory cytokines compared to freshly isolated macrophages. As shown in an eloquent study by Vaillant et al. [55], an increase in growth factors and cytokines can bias the numbers of stem cells present in normal or tumoral tissue, as well as alter progenitor/stem cell proliferation. Thus, it is possible that the secretion of proinflammatory cytokines by the LPS/IFN- $\gamma$-stimulated macrophages may have influenced humanization of the glands by stimulating progenitor cell response. Conversely, the increase in cytokine production by the macrophages potentially mimicked a wound response, thereby enhancing the outgrowth of the fibroblasts into the mammary fat pad in this model. Acute wounding was shown to increased tumor growth in a syngeneic mouse breast cancer model and, moreover, the effect of accelerated tumor growth due to wounding could be mimicked by acellular wound fluid [56]. We evaluated whether the effects of the macrophages on humanization could be stimulated using acellular-conditioned media (Additional File 6, Figure S4); however, concentrated macrophage-conditioned media were not capable of enhancing fibroblast humanization throughout the mammary gland. This suggests that either the physical presence of the macrophage in the mammary gland was necessary for enhanced humanization, or that human macrophage interactions with the murine stromal cells were necessary for the enhanced humanization observed.

Macrophage cytokine and chemokine production is reportedly suppressed by estrogen, often mediated by transcriptional or nongenomic repression of gene expression [27]. In the present study, estrogen had no effect on TNF $\alpha$ secretion $(60.9 \pm 1.1$ vs. $60.1 \pm 2.1 \mathrm{pg} /$ $\mathrm{ml}$ ); however, estrogen treatment alone or in combination with macrophage-conditioned media significantly decreased the concentration of the chemokines IL- 8 and IL-23, as well as the chemokine Eotaxin (Additional File 7 , Table S3, $\left.{ }^{*} P<0.05\right)$. We hypothesize that the estrogen-stimulated additive effects on enhanced fibroblast humanization of the gland are due to combinatory effects of estrogen-directed suppression of macrophagederived inhibitory cytokines/chemokines, as well as estrogen-stimulated proliferation in combination with other growth factors in vivo. The extensive and complex mechanisms of estrogen signaling are known to have a multitude of effects on breast cell growth and function [57-60]. Therefore, it is not surprising that exogenous estrogen augments the macrophage-stimulated proliferation of steroid-sensitive breast stromal cells in this in vivo model.

In this report we primarily investigated normal human breast cell interactions; however, this model is easily adaptable for studying primary human immune and stromal cell interactions in the breast tumor microenvironment. Many of the signaling mechanisms that control the outgrowth of cells throughout the breast during pubertal development and the continual repopulation of cells during steroid-driven cycles of growth are often exploited by tumor cells to support their parasitic growth and invasive properties. It is well acknowledged that immune cells play a significant and complex role in promoting tumorigenesis and metastasis [17]. Macrophages, in particular, have been shown to migrate to distinct tumor sites and, in response to the varying localized stimuli, release specific growth factors and molecules to regulate cancer cell proliferation, invasion, angiogenesis, and metastasis [13]. Our preliminary study observing the effect of macrophages on tumor formation demonstrated an increase in tumor cell engraftment and growth. Previous studies have shown a suppressive effect of normal fibroblasts on tumor formation [6,33-39], potentially explaining the low efficiency of tumorigenesis in the glands humanized with primary breast fibroblasts. Additionally, as stated above, the high level of cytokine/ chemokine production secretion from the macrophages potentially stimulated a wound response or augmented tumor progenitor cell proliferation similar to results shown in other studies [54-56]. It is well documented that inflammation and a wound-like signature promotes breast cancer tumorigenesis and is highly prognostic of breast cancer survival [61-63]. TNF $\alpha$ is a known mediator of the inflammatory response [63], and is a potential candidate for a mediator of the observed increase in tumorigenesis. It was recently shown that TNF $\alpha$ secretion from cultured macrophages was significantly increased after incubation with breast cancer tumor supernatants, and resulted in enhanced tumor cell invasion and adherence to endothelium [64]. Additionally, inhibition of TNF $\alpha$ has been shown to decrease breast cancer cell aggressive behavior, including metastasizing to bone [65]. Moreover, macrophages have been shown to play a key role in breast cancer; tumor-associated macrophages produce factors that promote tumor cell proliferation, migration, angiogenesis, tissue remodeling, reduce the local immune response to tumor cells, and are associated with poor prognosis in breast cancer patients $[17,64,66-68]$. While further studies are required to fully understand the role of macrophages in the humanized gland, this report presents the prospect of studying primary human macrophage/tumor interactions in a dynamic in vivo model; potentially further 
advancing our knowledge of the tumor-derived signals that promote distinct macrophage behavior.

\section{Conclusions}

Our findings demonstrate intricate immune and stromal cell paracrine interactions in a humanized in vivo model system. We confirmed our in vivo results with in vitro analyses, highlighting the value of this model to interchangeably substantiate in vitro and in vivo results. It is critical to understand the signaling networks that drive paracrine cell interactions to fully understand the basic mechanisms of breast cell function. Moreover, many of the signaling mechanisms that control the outgrowth of cells throughout the breast during pubertal development and the continual repopulation of cells during steroiddriven cycles of growth are often exploited by tumor cells to support their parasitic growth and invasive properties. This report presents a dynamic in vivo model to study primary human immune/fibroblast/epithelial interactions. This model can readily be applied to advance our knowledge of the stromal-derived signals that promote tumorigenesis.

\section{Additional material}

Additional file 1: Supplementary Table 1. Quantitative real time (qRT)PCR analysis of IFN/lipopolysaccharide (LPS) vs. colony-stimulating factor (CSF)-1 treatment on genes associated with macrophage differentiation.

Additional file 2: Supplementary Table 2. Real time (RT)-PCR primer sequences.

Additional file 3: Supplementary Figure 1. Representative images of macrophages treated in culture and real time (RT)- PCR analysis of the activation stages of macrophages in vitro.

Additional file 4: Supplementary Figure 2. Graphs of macrophage stimulation of primary breast fibroblast proliferation in vitro.

Additional file 5: Supplementary Figure 3. Ponceau staining of membranes, quantitation of zymography and western analysis, and representative images of ImageJ quantitation of stained tissue histosections.

Additional file 6: Supplementary Figure 4. Graph comparing glands humanized with conditioned media vs. macrophages.

Additional file 7: Supplementary Table 3. Table of values obtained from conditioned media ELISAs.

\footnotetext{
Abbreviations

ANOVA: one-way analysis of variance; ANG: angiopoietin; bFGF: basic fibroblasts growth factors; $\beta 2 \mathrm{M}$ : beta-2 microglobulin; EGF: epidermal growth factor; FBS: fetal bovine serum; FCS: fetal calf serum; DAPI: diamidino-2phenylindole; DMEM: Dulbecco's modified eagle medium; ELISA: enzymelinked immunosorbent assay; FISH: fluorescence in situ hybridization; GAPDH: glyceraldehyde-3-phosphate dehydrogenase; GFP: green fluorescent protein; H\&E: haematoxylin and eosin; HGF: hepatocyte growth factor; hTERT: human telomerase reverse transcriptase; IL: interleukin; LPS: lipopolysaccharide; IFN: interferon; MCP: monocyte chemoattractant protein; MMP: matrix metalloproteinase; PCNA: proliferating cell nuclear antigen; PCR: polymerase chain reaction; PDGF: platelet derived growth factor; PVDF: polyvinylidene fluoride; RANTES: regulated on-activation normal T cells expressed and excreted; SDS-PAGE: sodium dodecyl sulfate polyacrylamide gel
}

electrophoresis; TAM: Tumor associated macrophage; TARC: thymus and activation-regulated chemokine; TIMP: tissue inhibitor of metalloproteinase; TNF: tumor necrosis factor; VEGF: vascular endothelial growth factor.

\section{Acknowledgements}

This research was supported by the Center for Cancer Research, an Intramural Research Program of the National Cancer Institute, and by Breast Cancer Research Stamp proceeds awarded through competitive peer review. DAS and MAT were supported by NCI (R01 CA138255), NIEHS/NCI U01 ES019472, and UNC Breast SPORE P50 CA58233-18.

\section{Author details}

'Mammary Biology and Tumorigenesis Laboratory, Center for Cancer Research, National Cancer Institute, Bethesda, MD 20892, USA. ${ }^{2}$ North Carolina Central University, Department of Biology, Durham, NC 27707, USA. ${ }^{3}$ Laboratory of Cell and Molecular Biology, Center for Cancer Research, National Cancer Institute, Bethesda, MD 20892, USA. ${ }^{4}$ Department of Epidemiology, Gillings School of Public Health. University of North Carolina at Chapel Hill, Chapel Hill, NC 27599, USA.

\section{Authors' contributions}

JMF conceived and designed the study, performed or participated in all experiments, their analyses and interpretation, and wrote the manuscript. TCM and MK participated in macrophage isolation and in vivo experiments. EG assisted in data analysis, drafting and editing the manuscript. CHS provided the GFP viral particles and participated in editing the manuscript. DS and MAT performed the comparative PCR expression and analysis of differentiated macrophages. BKV conceived the study, assisted in data analysis and edited the manuscript. All authors read and approved the final manuscript.

\section{Competing interests}

The authors declare that they have no competing interests.

Received: 14 June 2011 Revised: 1 June 2012 Accepted: 25 June 2012 Published: 25 June 2012

\section{References}

1. McNally S, Martin F: Molecular regulators of pubertal mammary gland development. Ann Med 2011, 43:212-234.

2. McCave EJ, Cass CA, Burg KJ, Booth BW: The normal microenvironment directs mammary gland development. J Mammary Gland Biol Neoplasia 2010, 15:291-299.

3. Vonderhaar BK: Regulation of development of the normal mammary gland by hormones and growth factors. Cancer Treat Res 1988, 40:251-266.

4. Hovey RC, Trott JF, Vonderhaar BK: Establishing a framework for the functional mammary gland: from endocrinology to morphology. J Mammary Gland Biol Neoplasia 2002, 7:17-38.

5. Ramakrishnan R, Khan SA, Badve S: Morphological changes in breast tissue with menstrual cycle. Mod Pathol 2002, 15:1348-1356.

6. Kuperwasser C, Chavarria T, Wu M, Magrane G, Gray JW, Carey L, Richardson A, Weinberg RA: Reconstruction of functionally normal and malignant human breast tissues in mice. Proc Natl Acad Sci USA 2004, 101:4966-4971.

7. Schwertfeger $\mathrm{KL}$, Rosen JM, Cohen DA: Mammary gland macrophages: pleiotropic functions in mammary development. J Mammary Gland Biol Neoplasia 2006, 11:229-238.

8. Pollard JW: Role of colony-stimulating factor-1 in reproduction and development. Mol Reprod Dev 1997, 46:54-60, discussion 60-51.

9. Gouon-Evans V, Lin EY, Pollard JW: Requirement of macrophages and eosinophils and their cytokines/chemokines for mammary gland development. Breast Cancer Res 2002, 4:155-164.

10. Pollard JW, Hennighausen L: Colony stimulating factor 1 is required for mammary gland development during pregnancy. Proc Natl Acad Sci USA 1994, 91:9312-9316.

11. Gouon-Evans V, Rothenberg ME, Pollard JW: Postnatal mammary gland development requires macrophages and eosinophils. Development 2000, 127:2269-2282. 
12. Lanigan F, O'Connor D, Martin F, Gallagher WM: Molecular links between mammary gland development and breast cancer. Cell Mol Life Sci 2007, 64:3159-3184

13. Lewis CE, Pollard JW: Distinct role of macrophages in different tumor microenvironments. Cancer Res 2006, 66:605-612.

14. Pukrop T, Klemm F, Hagemann T, Gradl D, Schulz M, Siemes S, Trumper L, Binder C: Wnt 5a signaling is critical for macrophage-induced invasion of breast cancer cell lines. Proc Natl Acad Sci USA 2006, 103:5454-5459.

15. Wyckoff J, Wang W, Lin EY, Wang Y, Pixley F, Stanley ER, Graf T, Pollard JW, Segall J, Condeelis J: A paracrine loop between tumor cells and macrophages is required for tumor cell migration in mammary tumors. Cancer Res 2004, 64:7022-7029.

16. Ojalvo LS, Whittaker CA, Condeelis JS, Pollard JW: Gene expression analysis of macrophages that facilitate tumor invasion supports a role for Wntsignaling in mediating their activity in primary mammary tumors. $J$ Immunol 2010, 184:702-712.

17. Mukhtar RA, Nseyo O, Campbell MJ, Esserman L: Tumor-associated macrophages in breast cancer as potential biomarkers for new treatments and diagnostics. Expert Rev Mol Diagn 2011, 11:91-100.

18. Bingle L, Brown NJ, Lewis CE: The role of tumour-associated macrophages in tumour progression: implications for new anticancer therapies. $J$ Pathol 2002, 196:254-265.

19. Proia DA, Kuperwasser C: Reconstruction of human mammary tissues in a mouse model. Nat Protoc 2006, 1:206-214.

20. Stewart DA, Yang Y, Makowski L, Troester MA: Basal-like breast cancer cells induce phenotypic and genomic changes in macrophages. Mol Cancer Res 2012, 10:727-738

21. Telenius H, Pelmear AH, Tunnacliffe A, Carter NP, Behmel A, FergusonSmith MA, Nordenskjold M, Pfragner R, Ponder BA: Cytogenetic analysis by chromosome painting using DOP-PCR amplified flow-sorted chromosomes. Genes Chromosomes Cancer 1992, 4:257-263.

22. Telenius H, Carter NP, Bebb CE, Nordenskjold M, Ponder BA, Tunnacliffe A: Degenerate oligonucleotide-primed PCR: general amplification of target DNA by a single degenerate primer. Genomics 1992, 13:718-725.

23. Bustin SA, Benes V, Garson JA, Hellemans J, Huggett J, Kubista M, Mueller R, Nolan T, Pfaffl MW, Shipley GL, Vandesompele J, Wittwer CT: The MIQE guidelines: minimum information for publication of quantitative realtime PCR experiments. Clin Chem 2009, 55:611-622.

24. Fleming JM, Miller TC, Quinones M, Xiao Z, Xu X, Meyer MJ, Ginsburg E, Veenstra TD, Vonderhaar BK: The normal breast microenvironment of premenopausal women differentially influences the behavior of breast cancer cells in vitro and in vivo. BMC Med 2010, 8:27.

25. Fotherby K: Endocrinology of menstrual cycle and pregnancy. In Biochemistry of Steroid Hormones. Edited by: Making HL. Oxford: Blackwell Scientific Publications; 1984:409-440.

26. Pfeilschifter J, Koditz R, Pfohl M, Schatz H: Changes in proinflammatory cytokine activity after menopause. Endocr Rev 2002, 23:90-119.

27. Harkonen PL, Vaananen HK: Monocyte-macrophage system as a target for estrogen and selective estrogen receptor modulators. Ann NY Acad Sci 2006, 1089:218-227.

28. Sugarman BJ, Aggarwal BB, Hass PE, Figari IS, Palladino MA Jr, Shepard HM: Recombinant human tumor necrosis factor-alpha: effects on proliferation of normal and transformed cells in vitro. Science 1985, 230:943-945.

29. Battegay EJ, Raines EW, Colbert T, Ross R: TNF-alpha stimulation of fibroblast proliferation. Dependence on platelet-derived growth factor (PDGF) secretion and alteration of PDGF receptor expression. I Immunol 1995, 154:6040-6047.

30. Postlethwaite AE, Seyer JM: Stimulation of fibroblast chemotaxis by human recombinant tumor necrosis factor alpha (TNF-alpha) and a synthetic TNF-alpha 31-68 peptide. J Exp Med 1990, 172:1749-1756.

31. Rudolph-Owen LA, Matrisian LM: Matrix metalloproteinases in remodeling of the normal and neoplastic mammary gland. J Mammary Gland Biol Neoplasia 1998, 3:177-189.

32. Curran S, Murray GI: Matrix metalloproteinases: molecular aspects of their roles in tumour invasion and metastasis. Eur J Cancer 2000, 36:1621-1630.

33. Sadlonova A, Novak Z, Johnson MR, Bowe DB, Gault SR, Page GP, Thottassery JV, Welch DR, Frost AR: Breast fibroblasts modulate epithelial cell proliferation in three-dimensional in vitro co-culture. Breast Cancer Res 2005, 7:R46-59.
34. Shekhar MP, Werdell J, Santner SJ, Pauley RJ, Tait L: Breast stroma plays a dominant regulatory role in breast epithelial growth and differentiation: implications for tumor development and progression. Cancer Res 2001, 61:1320-1326.

35. Hu M, Yao J, Carroll DK, Weremowicz S, Chen H, Carrasco D, Richardson A, Violette S, Nikolskaya T, Nikolsky Y, Bauerlein EL, Hahn WC, Gelman RS, Allred C, Bissell MJ, Schnitt S, Polyak K: Regulation of in situ to invasive breast carcinoma transition. Cancer Cell 2008, 13:394-406.

36. Dong-Le Bourhis X, Berthois Y, Millot G, Degeorges A, Sylvi M, Martin PM, Calvo F: Effect of stromal and epithelial cells derived from normal and tumorous breast tissue on the proliferation of human breast cancer cell lines in co-culture. Int J Cancer 1997, 71:42-48.

37. van Roozendaal KE, Klijn JG, van Ooijen B, Claassen C, Eggermont AM, Henzen-Logmans SC, Foekens JA: Differential regulation of breast tumor cell proliferation by stromal fibroblasts of various breast tissue sources. Int J Cancer 1996, 65:120-125.

38. Proia DA, Kuperwasser C: Stroma: tumor agonist or antagonist. Cell Cycle 2005, 4:1022-1025

39. Barcellos-Hoff MH, Ravani SA: Irradiated mammary gland stroma promotes the expression of tumorigenic potential by unirradiated epithelial cells. Cancer Res 2000, 60:1254-1260.

40. Lin EY, Gouon-Evans V, Nguyen AV, Pollard JW: The macrophage growth factor CSF-1 in mammary gland development and tumor progression. $J$ Mammary Gland Biol Neoplasia 2002, 7:147-162.

41. Monks J, Henson PM: Differentiation of the mammary epithelial cell during involution: implications for breast cancer. J Mammary Gland Biol Neoplasia 2009, 14:159-170.

42. Carvalho-Freitas MI, Anselmo-Franci JA, Maiorka PC, Palermo-Neto J, Felicio LF: Prolactin differentially modulates the macrophage activity of lactating rats: possible role of reproductive experience. J Reprod Immunol 2011, 89:38-45.

43. O'Brien J, Lyons T, Monks J, Lucia MS, Wilson RS, Hines L, Man YG, Borges V, Schedin P: Alternatively activated macrophages and collagen remodeling characterize the postpartum involuting mammary gland across species. Am J Pathol 2011, 176:1241-1255.

44. Guo JJ, Su FX, Yao HR, Chen JS: Alternatively activated macrophages/ mononuclear phagocytes promote growth and invasion of breast cancer cell line SKBR3. Nan Fang Yi Ke Da Xue Xue Bao 2007, 27:410-413.

45. Seta N, Kuwana M: Human circulating monocytes as multipotential progenitors. Keio J Med 2007, 56:41-47.

46. Geissmann F, Manz MG, Jung S, Sieweke MH, Merad M, Ley K. Development of monocytes, macrophages, and dendritic cells. Science 2010, 327:656-661

47. Adib-Conquy M, Cavaillon JM: Gamma interferon and granulocyte/ monocyte colony-stimulating factor prevent endotoxin tolerance in human monocytes by promoting interleukin-1 receptor-associated kinase expression and its association to MyD88 and not by modulating TLR4 expression. J Biol Chem 2002, 277:27927-27934

48. Goldman AS, Chheda S, Garofalo R, Schmalstieg FC: Cytokines in human milk: properties and potential effects upon the mammary gland and the neonate. J Mammary Gland Biol Neoplasia 1996, 1:251-258.

49. Khalkhali-Ellis Z, Abbott DE, Bailey CM, Goossens W, Margaryan NV, Gluck SL, Reuveni M, Hendrix MJ: IFN-gamma regulation of vacuolar $\mathrm{pH}$, cathepsin $\mathrm{D}$ processing and autophagy in mammary epithelial cells. J Cell Biochem 2008, 105:208-218.

50. Harvat BL, Jetten $A M$ : Gamma-interferon induces an irreversible growth arrest in mid-G1 in mammary epithelial cells which correlates with a block in hyperphosphorylation of retinoblastoma. Cell Growth Differ 1996, 7:289-300.

51. Grunberg E, Eckert K, Karsten U, Maurer HR: Effects of differentiation inducers on cell phenotypes of cultured nontransformed and immortalized mammary epithelial cells: a comparative immunocytochemical analysis. Tumour Biol 2000, 21:211-223.

52. Wiktor-Jedrzejczak W, Bartocci A, Ferrante AW Jr, Ahmed-Ansari A, Sell KW, Pollard JW, Stanley ER: Total absence of colony-stimulating factor 1 in the macrophage-deficient osteopetrotic (op/op) mouse. Proc Natl Acad Sci USA 1990, 87:4828-4832.

53. Cohen PE, Chisholm O, Arceci RJ, Stanley ER, Pollard JW: Absence of colony-stimulating factor-1 in osteopetrotic (csfmop/csfmop) mice results in male fertility defects. Biol Reprod 1996, 55:310-317. 
54. Gyorki DE, Asselin-Labat ML, van Rooijen N, Lindeman GJ, Visvader JE: Resident macrophages influence stem cell activity in the mammary gland. Breast Cancer Res 2009, 11:R62.

55. Vaillant F, Lindeman GJ, Visvader JE: Jekyll or Hyde: does Matrigel provide a more or less physiological environment in mammary repopulating assays? Breast Cancer Res 2011, 13:108.

56. Stuelten CH, Barbul A, Busch Jl, Sutton E, Katz R, Sato M, Wakefield LM, Roberts AB, Niederhuber JE: Acute wounds accelerate tumorigenesis by a T cell-dependent mechanism. Cancer Res 2008, 68:7278-7282.

57. Asselin-Labat ML, Vaillant F, Sheridan JM, Pal B, Wu D, Simpson ER, Yasuda H, Smyth GK, Martin TJ, Lindeman GJ, Visvader JE: Control of mammary stem cell function by steroid hormone signalling. Nature 2010, 465:798-802.

58. Eden JA: Breast cancer, stem cells and sex hormones. Part 2: the impact of the reproductive years and pregnancy. Maturitas 2010, 67:215-218.

59. Fox EM, Andrade J, Shupnik MA: Novel actions of estrogen to promote proliferation: integration of cytoplasmic and nuclear pathways. Steroids 2009, 74:622-627.

60. Heldring N, Pike A, Andersson S, Matthews J, Cheng G, Hartman J, Tujague M, Strom A, Treuter E, Warner M, Gustafsson JA: Estrogen receptors: how do they signal and what are their targets. Physiol Rev 2007, 87:905-931.

61. Troester MA, Lee MH, Carter M, Fan C, Cowan DW, Perez ER, Pirone JR, Perou CM, Jerry DJ, Schneider SS: Activation of host wound responses in breast cancer microenvironment. Clin Cancer Res 2009, 15:7020-7028.

62. Hinohara K, Gotoh N: Inflammatory signaling pathways in self-renewing breast cancer stem cells. Curr Opin Pharmacol 2010, 10:650-654.

63. Goldberg JE, Schwertfeger KL: Proinflammatory cytokines in breast cancer: mechanisms of action and potential targets for therapeutics. Curr Drug Targets 2010, 11:1133-1146.

64. Eichbaum C, Meyer AS, Wang N, Bischofs E, Steinborn A, Bruckner T, Brodt P, Sohn C, Eichbaum MH: Breast cancer cell-derived cytokines, macrophages and cell adhesion: implications for metastasis. Anticancer Res 2011, 31:3219-3227.

65. Hamaguchi T, Wakabayashi H, Matsumine A, Sudo A, Uchida A: TNF inhibitor suppresses bone metastasis in a breast cancer cell line. Biochem Biophys Res Commun 2011, 407:525-530.

66. Shabo I, Svanvik J: Expression of macrophage antigens by tumor cells. Adv Exp Med Biol 2011, 714:141-150.

67. Lin CW, Shen SC, Ko CH, Lin HY, Chen YC: Reciprocal activation of macrophages and breast carcinoma cells by nitric oxide and colonystimulating factor-1. Carcinogenesis 2010, 31:2039-2048.

68. Berezhnaya NM: Interaction between tumor and immune system: the role of tumor cell biology. Exp Oncol 2010, 32:159-166.

\section{doi:10.1186/bcr3215}

Cite this article as: Fleming et al:: Paracrine interactions between primary human macrophages and human fibroblasts enhance murine mammary gland humanization in vivo. Breast Cancer Research 201214 : R97.

\section{Submit your next manuscript to BioMed Central and take full advantage of:}

- Convenient online submission

- Thorough peer review

- No space constraints or color figure charges

- Immediate publication on acceptance

- Inclusion in PubMed, CAS, Scopus and Google Scholar

- Research which is freely available for redistribution 